\section{Evidence for exclusion of a mutation in NRAMP as the cause of familial disseminated atypical mycobacterial infection in a Maltese kindred}

\author{
M Newport, M Levin, J Blackwell, M-A Shaw, R Williamson, C Huxley
}

pothesis that a mutation in NRAMP is responsible for the immunodeficiency observed in the affected children, we have typed eight markers in the region of human 2q34-q37 where NRAMP, the human homologue of Nramp, maps. We have shown discordance with the defect in one family and the chromosomes in the three affected children have different haplotypes making it unlikely that inheritance of an ancestral mutation in the NRAMP gene is the cause of increased mycobacterial susceptibility in this group of children.

( $(\mathcal{H}$ Med Genet 1995;32:904-906)
Department of

Biochemistry and Molecular Genetics, St Mary's Hospital Medical School, Imperial College of Science, Technology and Medicine, Norfolk Place, London W2 1PG, UK M Newport

$\mathrm{R}$ Williamson

C Huxley

Department of Paediatrics,

St Mary's Hospital Medical School, Imperial College of

Science,

Technology and

Medicine,

Norfolk Place,

London W2 1PG, UK

$M$ Newport

$M$ Levin

University of

Cambridge Clinical

School,

Department of

Medicine,

Level 5,

Addenbrooke's

Hospital,

Hills Road,

Cambridge CB2 2QQ

UK

J Blackwell

M-A Shaw

Correspondence to:

Dr Newport.

Received 6 April 1995

Revised version accepted for publication 9 June 1995
In mice, susceptibility to intracellular inin inbred strains is controlle creased susceptibility to myocabacte infection. The immunological defect observed in the affected children resembles that in mice homozygous for the Lsh/Ity/ Bcg susceptible allele. To test the hyFigure 1 Partial pedigree of the Maltese kindred showing segregation of alleles at eight loci, D2S211, TNP1, NRAN beneath each person genotyped. VIL1 is a $600 \mathrm{bp}$ BamHII/HindIII cDNA probe encoding the 3' region of the villin gene which detects a biallelic MspI polymorphism. ${ }^{2}$ IL $8 R B$ is a $1.5 \mathrm{~kb} \mathrm{cDNA}$ probe that detects a biallelic DraI polymorphism. ${ }^{3}$ TNP1 is an MspI RFLP within a $1.7 \mathrm{~kb}$ fragment of the human transition protein 1 (TNP1) gene which was amplified by PCR before digestion. ${ }^{4}$ DES is an EcoRV RFLP within a fragment of the desmin gene ${ }^{2}$ which was amplified with the primers $5^{\prime} G C A T G A A G A G G T A T A C T T G G C C 3^{\prime}$ and $5^{\prime} G A T G G C C A A G G T C A C A A A G T 3^{\prime}$ before digestion. D2S211, ${ }^{5} P A X 3,6 D 2 S 1471,{ }^{7}$ and NRAMP $P^{8}$ are dinucleotide repeats which were amplified by $P C R$. 
Proximal

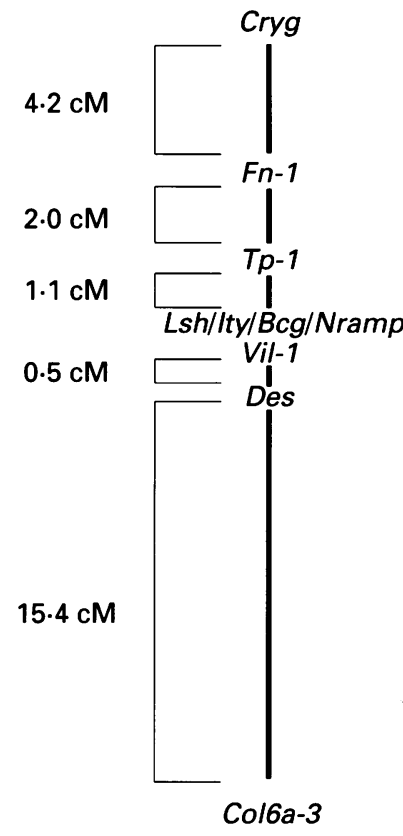

Distal

Proximal mouse chromosome 1

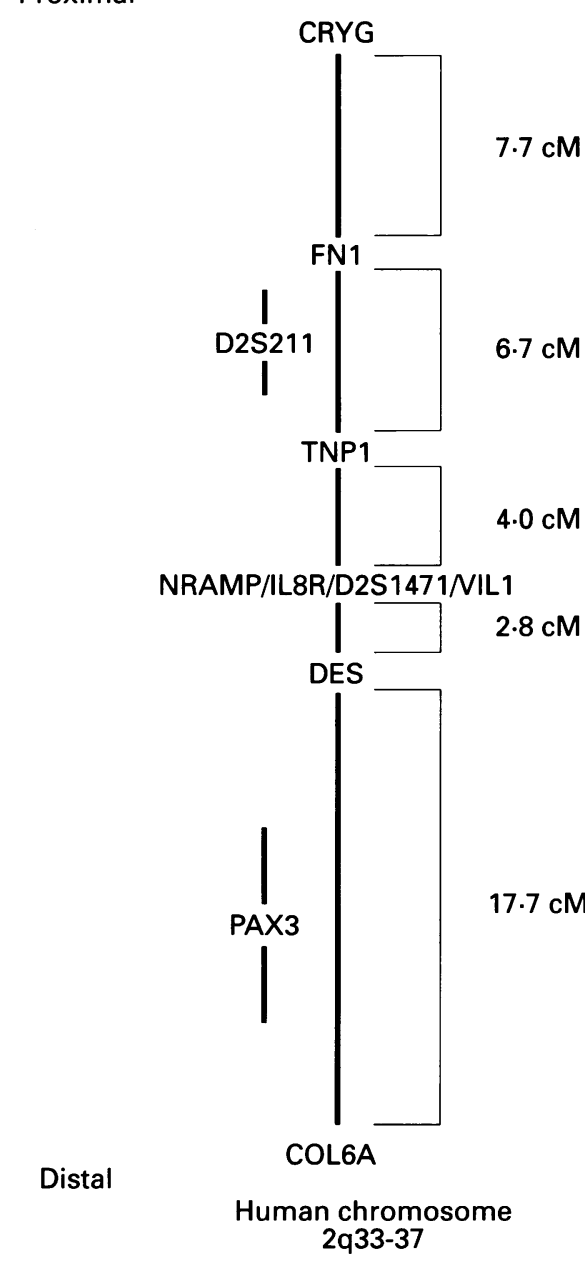

Figure 2 Schematic representation of the syntenic regions of proximal mouse chromosome $1^{1 \mathrm{l}}$ and human chromosome 2q33-37.312 Distances are indicated in centimorgans.

Four children from a village in Malta have presented with disseminated atypical mycobacterial infection. This is usually associated with underlying immunosuppression, whether inherited or acquired, and identification of the defect in this group of children would lead to a better understanding of the pathways involved in the control of infection by intracellular pathogens such as Mycobacterium tuberculosis, the cause of tuberculosis.

The clinical features are described in detail elsewhere. ${ }^{1}$ Each child is infected with a different bacterial species indicating an underlying defect in host immunity rather than exposure to an unusually virulent organism. However, extensive investigation has excluded all known immune defects usually associated with mycobacterial infection. ${ }^{1}$

The families are shown in fig 1 . In the large pedigree, two affected sibs are from a second cousin marriage (family B) while the third affected (family A) is related to the first two as a fourth cousin on both parents' sides. The exact relationship linking the fourth affected child to the large pedigree has not been determined, but she comes from the same relatively isolated village. The presence of two affected sibs in a consanguineous marriage is indicative of autosomal recessive inheritance. Owing to the high degree of inbreeding and the rarity of the disease, it is likely that all four children have the same autosomal recessive disorder inherited from a common ancestor.

In mice, a recessive mutation in a single gene denoted Lsh, Ity, or Bcg causes susceptibility to intracellular pathogens such as leishmania, salmonella, and mycobacteria. ${ }^{9}$ Macrophages from homozygous mutant mice show a variety of specific defects in tumoricidal and antimicrobial activity. ${ }^{9}$ The affected children have increased susceptibility to mycobacterial infection and abnormalities of macrophage priming and activation that are very similar to those observed in susceptible mice. ${ }^{1}$

A candidate for the $L s h / I t y / B c g$ gene has been cloned and designated natural resistance associated macrophage protein (Nramp). Nramp is located on the proximal region of mouse chromosome $1^{10}$ which is syntenic to human chromosome $2 \mathrm{q}$, as shown in fig 2 . In the mouse, Nramp is located between $V i l$ and $T p-1$, about $50 \mathrm{~kb}$ from $V i l .^{10}$ Conserved synteny places the human NRAMP gene between markers D2S1471/VIL1 and markers TNP1/ D2S211. This is confirmed by physical mapping studies which also show that the human NRAMP gene is located approximately $155 \mathrm{~kb}$ proximal to VIL1 on chromosome $2 \mathrm{q} 35 .{ }^{38}$

DNA from three affected children and their parents and grandparents were typed with eight polymorphic loci, the positions of which are shown in fig 2. As can be seen in fig 1 all the families show mendelian inheritance of the markers and no recombination events have occurred.

If a mutation in the human NRAMP gene were responsible for the immunodeficiency seen in this Maltese kindred, and the mutation occurred in a common ancester, then the affected children would share a haplotype for the locus and would be homozygous for it. ${ }^{13}$ However, it can be seen that the six chromosomes carry five different haplotypes. In addition, the two sibs in family A, III 1 (who is affected) and III.2 (who is not affected), have inherited the same genotype from their parents. This excludes a recessive mutation in NRAMP unless III. 2 has the mutation but has not shown the phenotype. This seems unlikely as she is 6 years old, three times the age of onset of the affected children.

If the children have inherited a recessive mutation, these data indicate that the mutation is unlikely to be in the human NRAMP gene.

M Newport is supported by the St Mary's Hospital Medical School Special Trustees. Work in the Cambridge laboratory is supported by the Wellcome Trust. We thank Dr John Todd for making available the primer sequences for the microsatellite D2S1471.

1 Levin M, Newport MJ, D'Souza S, et al. Familial disseminated atypical mycobacterial infection in early childhood: a human mycobacterial susceptibility gene? Lancet 1995;345:79-83.

2 Shaw MA, Atkinson SE, Paulin D, Blackwell JM. EcoRV RFLP of the desmin (DES) gene and Msp1 RFLP of the RFLP of the desmin (DES) gene and Msp1 RFLP of the
villin(VIL) gene on human chromosome 2. Hum Mol villin(VIL) gene on

3 White JK, Shaw MA, Barton $\mathrm{CH}$, et al. Genetic and physical mapping of $2 \mathrm{q} 35$ in the region of the NRAMP and IL8R mapping of $2 \mathrm{q} 35$ in the region of the NRAMP and IL8R

4 Hoth CF, Engel W. Two RFLPs at the TNP1 locus. Nucleic Acids Res 1991;19:6979.

5 Barber TD, Morell R, Johnson DH, Asher JH, Friedman TB. A highly informative dinucleotide repeat polymorphism at the D2S211 locus linked to ALPP, FN1 and TNP1. Hum Mol Genet 1993;2:88. 
6 Wilcox ER, Rivolta MN, Ploplis B, Pottert SB, Fex J. The PAX3 gene is mapped to human chromosome 2 together with a highly informative CA dinucleotide repeat. Hum Mol Genet 1992;1:215.

7 Copeman JB, Cucca F, Hearne CM, et al. Linkage disequilibrium mapping of a type 1 diabetes susceptibility equilibru 17) to 2q31-q33. Nature Gen 1995;9:80-5. gene (IDDM ( ganization and sequence of the human NRAMP gene: identification and mapping of a promoter region poly-
morphism. Mol Med 1995;1:194-205. Blorphis. Blackwell JM. The macrophage resistance gene, $L$ sh/Ity/Bcg.
Res Immunol 1989;140:767-828.
10 Vidal SM, Malo D, Vogan K, Skamene E, Gros P. Natural resistance to infection with intracellular parasites: isolation of a candidate for Bcg. Cell 1993;73:469-85.

11 Malo D, Vidal SM, Hu J, Skamene E, Gros P. High resolution linkage map in the vicinity of the host resistance locus Bcg. Genomics 1993;16:655-63.

12 Shaw MA, Atkinson S, Dockerell $\mathrm{H}$, et al. An RFLP map for 2q33-q37 from multicase mycobacterial and leishmanial disease families: no evidence for an $\mathrm{Lsh} / \mathrm{Ity} / \mathrm{Bcg}$ gene homologue influencing susceptibility to leprosy. Ann Hum Genet 1993;57:251-71.

13 Jorde LB. Linkage disequilibrium as a gene-mapping tool Am $\mathcal{f}$ Hum Genet 1995;56:11-14. 